\title{
A Psicologia no Curso de Pedagogia da antiga Faculdade de Filosofia, Ciências e Letras de Uberlândia (Minas Gerais, Brasil, 1960-1970)
}

\author{
Psychology in the Pedagogy Course of the former Faculty of Philosophy, Sciences, and \\ Letters of Uberlandia (Minas Gerais, Brazil, 1960-1970)
}

La Psicología en el Curso de Pedagogía de la antigua Facultad de Filosofía, Ciencias y Letras de Uberlândia (Minas Gerais, Brasil, 1960-1970)

\author{
Claudio Gonçalves Prado \\ Universidade Federal de Uberlândia, Brasil \\ http://lattes.cnpq.br/9478460919367913 \\ https://orcid.org/0000-0002-4801-7835 \\ claudiogprado@ufu.br \\ Décio Gatti Júnior \\ Universidade Federal de Uberlândia, Brasil \\ http://lattes.cnpq.br/0164067095554570 \\ https://orcid.org/0000-0002-5876-6733 \\ degatti@ufu.br
}

\section{Resumo}

Trata-se da busca de compreensão da importância e dos conteúdos disciplinares vinculados à Psicologia na primeira década de funcionamento, entre 1960 e 1970, do Curso de Pedagogia da antiga Faculdade de Filosofia, Ciências e Letras de Uberlândia (Minas Gerais, Brasil). Partiuse de ideias de Certeau (1979), Chervel (1990), Santos (2007) e Goodson (2008 e 2010). Examinaram-se os conteúdos disciplinares, bem como o depoimento de egressa do curso. Percebeu-se a presença significativa dos saberes psicológicos, com mais de uma disciplina, oferecidas ao longo de todo curso, o que alcançava um quinto da carga-horária total (570h/a, em 2.800h/a). Além das tradicionais Psicologia Geral e Educacional, também foi possível conhecer a disciplina nomeada Psicologia Especial, na qual, à época, enfatizaram-se conhecimentos da Psicopatologia. Concluiu-se que a Psicologia tinha centralidade na formação dos pedagogos na Faculdade de Filosofia, Ciências e Letras de Uberlândia na primeira década de funcionamento do Curso de Pedagogia, ainda que mediante dificuldades quanto à qualificação docente, o que prejudicou a especificidade da temática educacional.

Palavras-chave: Educação. História. Disciplina. Psicologia. Psicopatologia. 


\begin{abstract}
This text is about the search to understand the importance and disciplinary contents linked to Psychology in the first decade of operation, within 1960 and 1970, of the Pedagogy Course of the former Faculty of Philosophy, Sciences, and Letters of Uberlandia (Minas Gerais, Brazil). It was based on the ideas of Certeau (1979), Chervel (1990), Santos (2007), and Goodson (2008 and 2010). By examining the disciplinary contents, as well as the testimony of one egress student of the course, it was perceived the significant presence of psychological knowledge, with more than a discipline, offered throughout the course, which reached a fifth of the total working hours $(570 \mathrm{~h} / \mathrm{c}$, in $2800 \mathrm{~h} / \mathrm{c})$. Besides the traditional General and Educational Psychology, it was possible to know the discipline called Especial Psychology, in which, at the time, emphasized Psychopathology knowledge. The conclusion was that Psychology was central in the formation of educators at the Faculty of Philosophy, Sciences, and Letters of Uberlandia in the first decade of the Pedagogy Course, even with the difficulties concerning teachers' qualifications, which impaired the specificity of the educational theme.
\end{abstract}

Key words: Education. History. Discipline. Psychology. Psychopathology.

\title{
Resumen
}

Se trata de la búsqueda de comprensión de la importancia y de los contenidos disciplinares vinculados a la Psicología en la primera década de funcionamiento, entre 1960 y 1970, del Curso de Pedagogía de la antigua Facultad de Filosofía, Ciencias y Letras de Uberlândia (Minas Gerais, Brasil). Se partió de las ideas de Certeau (1979), Chervel (1990), Santos (2007) y Goodson (2008 y 2010). Fueron examinados los contenidos disciplinares, bien como el testimonio de una egresada del curso. Se observó la presencia significativa de los saberes psicológicos, con más de una disciplina, ofrecidas a lo largo de todo el curso, lo que alcanzaba un quinto de la carga horaria total $(570 \mathrm{~h} / \mathrm{a}$, en $2.800 \mathrm{~h} / \mathrm{a})$. Además de las tradicionales Psicología General y Educacional, también fue posible conocer la disciplina denominada Psicología Especial, en la cual, para la época, se enfatizaban conocimientos de la Psicopatología. Se concluye que la Psicología tenia centralidad en la formación de los pedagogos de la Facultad de Filosofía, Ciencias y Letras de Uberlândia en la primera década de funcionamiento del Curso de Pedagogía, aun con dificultades en cuanto a la cualificación docente, lo que perjudico la especificidad de la temática educacional.

Palabras-clave: Educación. Historia. Disciplina. Psicología. Psicopatología. 


\section{Introdução}

O presente artigo objetiva refletir sobre conteúdos elementares da ciência psicológica presentes em cursos de formação de professores, especificamente no Curso de Pedagogia. Nessa direção, cumpre lembrar que Tardif (2010, p.361-362) considera a relevância dos conhecimentos da Psicologia para o campo da Pedagogia, comparando-a à importância da Biologia para o campo da Medicina e da Física e da Matemática para o campo da Engenharia. Nesse sentido, quando se observam os conteúdos programáticos dos cursos de formação de professores nas instituições de educação superior brasileiras, é possível encontrar um determinado corpo teórico que toma a Psicologia como uma área importante na formação dos educadores e para a compreensão do processo educativo. Portanto, alguns saberes são fundamentais para a elaboração de um conjunto de conhecimentos.

A respeito das contribuições das fontes de pesquisa para os trabalhos historiográficos, Michel de Certeau (1979) analisa o processo de operação histórica e destaca aspectos importantes na prática efetiva do historiador, envolvendo um lugar e procedimentos de análise.

Toda pesquisa historiográfica é articulada a partir de um lugar de produção sócio-econômico, político e cultural. Implica um meio de elaboração circunscrito por determinações próprias: uma profissão liberal, um posto de estudo ou de ensino, uma categoria de letrados etc. Encontra-se, portanto, submetida a opressões, ligada a privilégios, enraizada em uma particularidade. É em função desse lugar que se instauram os métodos, que se precisa uma topografia de interesses, que se organizam os dossiers e as indagações relativas aos documentos (Certeau, 1979, p.18).

Nesse mesmo trabalho, o autor também faz referências ao estudo das disciplinas ao afirmar que "nascimentos de 'disciplinas' se encontram ligados à criação de grupos" (Certeau, 1979, p.21). Desta forma, tanto o local enquanto objeto de investigação quanto os recursos técnicos a serem empregados tem relevância significativa para a investigação histórica de um determinado tema.

Antoine Prost (2008), por sua vez, alerta para o fato de que a história precisa conciliar contradições: a necessidade de fatos extraídos de fontes, apesar de os vestígios não significarem fontes, afirmando que a História apresenta um caráter de prática empírica. Desta forma, conclui que "a complexidade da história como prática remete à própria complexidade de seu objeto" (Prost, 2008, p.135).

As fontes documentais também representam um elemento relevante para a pesquisa historiográfica. Em tese defendida por Rosângela Guimarães (2012), ela chama a atenção para a importância do corpus documental, ao afirmar que

Na prática da operação historiográfica, a constituição de um corpus documental significa um momento crucial, não só pelo trabalho que acarreta ao pesquisador, mas também pelas implicações teóricas envolvidas neste ato primordial da investigação (Guimarães, 2012, p.16).

Maria Teresa Santos (2007), ao abordar a trajetória e a situação do ensino da História da Educação em Portugal, salienta que no percurso letivo de uma disciplina, "algumas datas são incontornáveis referências, alguns planos de estudos são insubstituíveis registos de configuração e alguns docentes e respectivas obras são inegáveis marcos de orientação" (Santos, 2007, p.75). E, em seguida, acentua a importância da utilização de documentos como fontes de pesquisa: 
Datas, planos de estudos, docentes e obras concorrem para fazer a historicidade da disciplina, ou seja, para desenhar o percurso de acesso ao seu entendimento: o significado da dimensão substantiva, o sentido dos objectivos, a pertinência do conteúdo para a formação de professores e as circunstâncias concretas da sua introdução curricular e reconhecimento institucional. Todos estes elementos se inscrevem e constituem a memória da História da Educação. Memória que lhe dá identidade e, assim, a salvaguarda [...] da idiotice do saber abstrato sem factos, sem rostos, sem textos, sem temas nem questões (Santos, 2007, p.75).

Deste modo, diversas fontes documentais podem servir como referência para uma pesquisa em relação a um determinado recorte histórico. Os documentos oficiais são importantes no entendimento da construção de uma disciplina escolar, porque trazem determinações legislativas para a execução do programa curricular. Assim, uma fonte apenas se torna relevante, sejam documentos oficiais, diários, cartas ou material audiovisual ou fotográfico, quando recebe o devido tratamento.

As fontes orais, por seu turno, são de grande importância na pesquisa historiográfica, apesar da necessidade de atenção para os cuidados e os riscos ao se fazer pesquisa baseada em relatos orais. Thompson (2002) fez uma análise de suas próprias experiências ao longo de trinta anos.

Devo dizer, desde logo, que tenho forte preferência por uma definição mais ampla: entendo por "história oral" a interpretação da história e das mutáveis sociedades e culturas através da escuta das pessoas e do registro de suas lembranças e experiências (Thompson, 2002, p.09).

O autor parte de duas premissas básicas: a história oral é um método essencialmente interdisciplinar e deve unir a evidência da pesquisa qualitativa e quantitativa. Ao discutir as potencialidades dessa metodologia, apresenta áreas de investigação nesta abordagem e conclui sobre a importância da história oral para ajudar a compreender melhor o passado e criar memórias nacionais, construindo um futuro mais amável e democrático.

Todavia, parece importante lembrar das ressalvas feitas por Pierre Bourdieu (2005) a respeito dos riscos contidos nos estudos biográficos a partir da história oral. "A história de vida é uma dessas noções do senso comum que entraram como contrabando no universo científico" (Bourdieu, 2005, p.183). O autor chama a atenção para um fenômeno que chamou de "ilusão biográfica", no qual acontece uma "criação artificial de sentido" por parte do investigado, com a cumplicidade do investigador, diante do que é necessário evitar que se construam representações de histórias idealizadas, sem considerar as contradições existentes na história de vida de cada indivíduo (Bourdieu, 2005).

Ivor Goodson (2008), por seu turno, na temática dos estudos biográficos e das histórias de vida de profissionais, quando reflete sobre as políticas de currículo e de escolarização, levanta um ponto importante que consiste no reconhecimento da necessidade de se compreender aspectos pessoais e biográficos antes de analisar o social e o político; essa perspectiva representaria uma crítica a iniciativas governamentais que prescindem dos objetivos e experiências pessoais dos principais executores dos conteúdos curriculares: os docentes (Moreira, 2008, p.8). Para ele, uma consequência significativa consistiria no fato das reformas praticadas tornarem-se sem sentido e contraditórias.

A importância das histórias de vida e as narrativas respaldariam ainda mais o recurso às fontes orais como fontes históricas, pois o poder da memória de atualizar as vivências do passado complementa-se à possibilidade de reconhecimento da consciência do professor sobre o seu 
potencial, dado que as entrevistas e suas narrativas não possibilitam apenas o conhecimento do outro, mas favorecem a colaboração entre entrevistador e entrevistado (Moreira, 2008, p.10).

Para o autor, no que se refere às contribuições dos estudos biográficos na educação, é relevante discutir as missões pessoais e desenvolvimento pessoais. Estaria correta a premissa de que tudo não vai muito bem com as escolas, mas seria falso pensar que as reformas e mudanças provavelmente ajudariam a melhorar a situação. Assim, ao mencionar o papel do professor como parte importante do sistema de transmissão dos conhecimentos, ressalta que os aspectos técnicos do profissionalismo do docente são enfatizados e não sua biografia profissional, ou seja, "as missões e envolvimentos pessoais que sustentam o sentido que o professor tem de vocação e de profissionalismo dedicado" (Goodson, 2008, p.108).

\section{A História disciplinar e os currículos prescritos}

André Chervel tornou-se um autor importante no campo de pesquisa a partir de seu artigo "História das disciplinas escolares: reflexões sobre um campo de pesquisa", publicado originalmente em 1988, na França, e em 1990, no Brasil. No início de seu texto, ele enfatiza os interesses que começavam a se delinear neste campo de pesquisa.

Mais recentemente, tem-se manifestado uma tendência, entre os docentes, em favor de uma história de sua própria disciplina. Dos conteúdos do ensino, tais como são dados nos programas, o interesse então evoluiu sensivelmente para uma visão mais global do problema, associando-se as ordens do legislador ou das autoridades ministeriais ou hierárquicas à realidade concreta do ensino nos estabelecimentos, e, algumas vezes, até mesmo às produções escritas dos alunos (Chervel, 1990, p.177).

Esse esclarecimento remete a duas condições importantes para esta área de estudo: a legislação e a realidade em que se inserem os estudantes. Em seguida, o autor reflete sobre o conceito de disciplina escolar, as ciências de referência, com destaque para a pedagogia e as metodologias de ensino e o objeto de estudo, considerando três problemas: a gênese, a função e o funcionamento da disciplina escolar.

Neste ponto, Chervel destaca as diferenças entre as disciplinas de ensino primário e do secundário, e do ensino superior. Essas possíveis diferenças metodológicas de investigação implicariam na distinção entre disciplina escolar e disciplina acadêmica (Warde, 1998; Borges, 2013). Em relação à disciplina acadêmica, Chervel considera que no ensino superior,

o mestre ignora aqui a necessidade de adaptar a seu público os conteúdos de acesso difícil, e de modificar esses conteúdos em função das variações de seu público: nessa relação pedagógica, o conteúdo é uma invariante. Todos os problemas de ensino se remetem aos problemas de comunicação: eles são, quando muito, de ordem retórica (Chervel, 1990, p.185).

Ao discutir os objetivos do ensino escolar, André Chervel identifica, classifica e organiza diversas finalidades: religiosas, sócio-políticas, culturais e de ordem psicológica. Porém, analisando o século XIX, ele levanta a problemática entre o conteúdo prescrito e a realidade pedagógica: "De que lado colocaremos as finalidades? Do lado da lei ou do lado das práticas concretas?" (Chervel, 1990, p.189). E mais adiante, ele conclui que "o estudo das finalidades não pode, pois, de forma alguma, abstrair os ensinos reais. Deve ser conduzido simultaneamente sobre os dois planos, e utilizar uma dupla documentação, a dos objetivos fixados e a da realidade pedagógica" (Chervel, 1990, p.191). 
A questão da finalidade da disciplina aparece diversas vezes ao longo de seu trabalho, inclusive ao reconhecer que a disciplina muda ao longo do tempo porque sua finalidade pode ter mudado. Assim, ressalta, como primeira tarefa do historiador, a busca do conhecimento dos conteúdos explícitos do ensino disciplinar, o corpus do conhecimento. O papel da pedagogia também é lembrado quanto à forma de transmissão desse conteúdo.

Essa interpretação dos fatos educacionais, e do papel da "pedagogia" no ensino se opõe, já se viu, a uma longa tradição que se baseia sobre um corte estrito entre a instrução, de um lado, considerada como um conteúdo, e a pedagogia, de outro, que não seria senão a forma de transmissão desse conteúdo. É notável que, nos debates frequentemente agitados, partidários e adversários de novos métodos pedagógicos possam muito bem se entender com relação a esse ponto. A realidade premente da prática docente não permite essa separação, a não ser comprometendo igualmente a existência das finalidades (Chervel, 1990, p.205-206).

É possível perceber que, ao analisar a diferenciação entre o prescrito e o realizado, os recursos pedagógico-metodológicos utilizados também influenciam no alcance das finalidades do ensino, o que remete à necessidade de conhecer as práticas pedagógicas realizadas no desenvolvimento de uma disciplina. As fontes de pesquisa que permitem conhecer as finalidades compreendem programas e planos de ensino, legislação predominante, manuais e bibliografia recomendada e as ideias pedagógicas no período estudado, enquanto a realidade pedagógica pode ser investigada a partir de cadernos de alunos, provas aplicadas e depoimentos dos atores sociais envolvidos.

Chervel também abordou a questão da distribuição das disciplinas escolares e, inevitavelmente, colocou em questão o problema da hierarquização. As disciplinas podem ocupar uma condição de maior visibilidade e reconhecimento social, apresentando uma maior carga horária, um docente de maior prestígio, um currículo mais abrangente, em detrimento de outras "matérias". Ao analisar o estudo da língua francesa, ele ressalta um papel de destaque em relação à mesma no ensino primário e secundário.

Em torno de uma mesma finalidade colaboram aqui os diferentes ensinos. A mesma "disciplina", no sentido forte do termo, repartiu-se entre a quase totalidade das "matérias", ou daquilo que se convencionou chamar atualmente as "disciplinas", no sentido fraco. Essas mantêm então entre elas uma "solidariedade didática" cuja importância deve tanto menos ser negligenciada quanto estes fenômenos arriscam a passar desapercebidos (Chervel, 1990, p.215).

A partir dessa problemática, pode-se pensar: qual o lugar da Psicologia, enquanto disciplina acadêmica, no curso de Pedagogia? Seu conteúdo sofreu desdobramentos ou repartiuse entre outras matérias?

Ivor Goodson apresenta uma série de capítulos na obra intitulada "Currículo: teoria e história" (2010). Na apresentação de seu livro, Silva (2010, p.7) destaca que o currículo está em constante fluxo e transformação, sendo que a análise histórica dele deve procurar captar rupturas e grandes descontinuidades. Assim, a análise do processo de construção de um programa curricular não deve ser entendida como um processo epistemológico inocente, em que os acadêmicos responsáveis estariam agindo de forma neutra, sem grandes interesses, ao definir os conteúdos escolares a serem oferecidos na disciplina. 
O processo de elaboração de um currículo acadêmico não costuma ser lógico, mas social, em que fatores epistemológicos e intelectuais coexistem com determinantes sociais pouco nobres e formais. Nesse sentido, é possível reconhecer uma menor importância das deliberações sociais racionais do currículo sobre o conhecimento, o que remete a atenção para "o caráter caótico e fragmentário das forças que o moldam e determinam" (Silva, 2010, p.9). Uma crítica de Silva (2010) remete à análise de leis e regulamentos em relação aos processos informais e interacionais.

É igualmente importante que uma história do currículo não se detenha nas deliberações conscientes e formais a respeito daquilo que deve ser ensinado nas escolas, tais como leis e regulamentos, instruções, normas e guias curriculares, mas que investigue também os processos informais e interacionais pelos quais aquilo que é legislado é interpretado de diferentes formas, sendo frequentemente subvertido e transformado (Silva, 2010, p.9).

O estudo da origem dos conteúdos curriculares consegue evocar a importância de se conhecer melhor as nuances existentes na construção do programa curricular de uma disciplina acadêmica e seus desdobramentos na prática. Ao estudar a história dos currículos, no intuito de elaborar uma teoria sobre o assunto, Goodson (2010, p.24-25) estabelece a distinção entre a definição "pré-ativa" de currículo e a realização "interativa" do currículo.

Esta distinção remete a um campo fecundo de investigação que se concatena ao campo da história das disciplinas escolares, na questão da relação entre o prescrito e o realizado. A posição de Goodson parece reforçar aspectos peculiares ao campo da história das disciplinas, como a importância dos elementos que norteiam a construção de ementas e programas, como a legislação, por exemplo.

A partir deste exemplo talvez se entenda como é importante compreender as lutas precedentes em torno da definição pré-ativa de currículo. Nessas circunstâncias é politicamente ingênuo e conceitualmente inadequado afirmar que "o importante é a prática em sala de aula" (da mesma forma que é uma ignorância querer excluir a política da educação). O que importa ainda, e mais obviamente neste caso, é compreender os parâmetros anteriores à prática. O que também deveria ser claro, no entanto, é que não são simplesmente as definições intelectuais que emanam do currículo escrito as que possuem força (Goodson, 2010, p.21-22).

Neste sentido, apesar do autor defender uma valorização do prescrito em relação à realidade prática como aspecto fundamental para o conhecimento da história do currículo, e também, da discussão a respeito da disciplina escolar e/ou acadêmica, ele reconhece a importância de não se ater apenas a este currículo "pré-ativo". Neste momento, seria oportuno questionar a possibilidade de inverter a importância desses polos de discussão e começar a pensar sobre o quanto a realidade da sala de aula pode se sobrepujar ao currículo meramente planejado conforme legislação e ementas vigentes.

Essa inversão consistiria em uma forma de evitar também o risco de se adotar as teses da dicotomia completa entre currículo escrito e currículo ativo. Estas distinções de Ivor Goodson sobre o prescrito e o ativo remetem à mesma perspectiva crítica de André Chervel ao diferenciar objetivos fixados e realidade pedagógica. 


\section{Os conteúdos prescritos de Psicologia do Curso de Pedagogia na Faculdade de Filosofia, Ciências e Letras de Uberlândia (1960-1970)}

As mudanças importantes que influenciariam o surgimento da Universidade Federal de Uberlândia (UFU) tiveram sua origem no final da década de 1950, com a criação de cursos de graduação em faculdades isoladas, mantidas pela Igreja Católica e pela sociedade civil. Porém, a regulamentação e oficialização da universidade ocorreu apenas em 24 de maio de 1978 por meio da Lei 6.532, que transformou a Universidade de Uberlândia (UnU) em uma universidade federal (Brasil, 1978). Vários acontecimentos foram importantes para esse desenvolvimento.

No início dos anos de 1950, a cidade de Uberlândia, situada na região do Triângulo Mineiro, interior de Minas Gerais, a $535 \mathrm{~km}$ de Belo Horizonte, capital do Estado, já apresentava um índice significativo de crescimento e expansão na economia. Porém, no campo cultural, sentia-se a necessidade de desenvolvimento, pois ainda não havia cursos de nível superior: "Uberlândia precisa de uma faculdade" (O Repórter, 1952, citado em Caetano; Dib, 1988, p.XXI). A criação de cursos de graduação representava a possibilidade de desenvolvimento cultural para a cidade.

Na busca de superação das deficiências de cultura e educação na cidade, ao final da década de 1950 e início da década de 1960, em que a cidade contava com aproximadamente 80 mil habitantes, surgiram as primeiras escolas e faculdades superiores ${ }^{1}$. Se a década de 1960 foi marcante na História mundial, com grandes transformações políticas e culturais, seja nas tensões provocadas pela Guerra Fria ou pela mudança de comportamento dos jovens e sua rebeldia, Uberlândia também vivenciou um período de efervescência cultural com o desenvolvimento do Ensino Superior na cidade ${ }^{2}$.

O contexto do surgimento das primeiras faculdades envolve um conflito entre laicidade, e a religiosidade católica. As conversas dos religiosos com o Bispo sobre a criação da diocese e a fundação do Colégio das Irmãs, no qual se formavam normalistas, e a necessidade de desenvolvimento cultural na cidade que prosperava economicamente foram fatores significativos e relevantes para o surgimento da Faculdade de Filosofia, Ciências e Letras de Uberlândia (FFCLU), oferecendo, inicialmente, os cursos de Pedagogia e de Letras em 1960.

As primeiras faculdades e os primeiros cursos promoveram um entusiasmo crescente entre aqueles que se interessavam por cultura e educação. O Quadro 1, a seguir, apresenta as faculdades e cursos que surgiram nesse período, e que, futuramente, originariam, primeiramente, a Universidade de Uberlândia (UnU) e, posteriormente, em 1978, a Universidade Federal de Uberlândia.

\footnotetext{
${ }^{1}$ A educação, na época, era constituída por algumas escolas secundárias (ou ginásios), escolas de contabilidade, cursos técnicos e cursos primários (Caetano; Dib, 1988, p.08).

${ }^{2}$ Segundo Saviani (2008, p.44), “a década de 1960 foi uma época de intensa experimentação educativa. Além dos colégios de aplicação e das escolas experimentais que se consolidaram nesse período (Warde, 1989), surgiram os ginásios vocacionais (Ribeiro, 1989), deu-se grande impulso à renovação do ensino de matemática (Motejunas, 1989) e de ciências (Krasilchik, 1989), colocando em ebulição o espaço acadêmico da pedagogia. Essa década, contudo, não deixou também de assinalar o esgotamento do modelo renovador, o que se evidencia pelo fato de que as experiências mencionadas se encerram no final dos anos 60, quando também são fechados o CBPE e o CRPEs a ele ligados".
} 
Quadro 1 - Relação das escolas e faculdades superiores implantadas em Uberlândia até 1963.

\begin{tabular}{|c|l|l|}
\hline Criação & \multicolumn{1}{|c|}{ Escolas/Faculdades Isoladas } & \multicolumn{1}{|c|}{ Cursos } \\
\hline 1957 & Conservatório Musical de Uberlândia* & Música \\
\hline 1959 & Faculdade de Filosofia, Ciências e Letras de Uberlândia & Pedagogia; Letras \\
\hline 1960 & Faculdade de Direito de Uberlândia & Direito \\
\hline 1961 & Faculdade Federal de Engenharia & Engenharia \\
\hline 1963 & Faculdade de Ciências Econômicas de Uberlândia & Ciências Econômicas \\
\hline
\end{tabular}

* O reconhecimento do curso ocorreu no ano de 1975.

Fonte: Elaborado pelos autores, a partir de Borges (2013).

Nota-se que a Pedagogia destaca-se como um dos primeiros cursos da Faculdade de Filosofia, Ciências e Letras de Uberlândia, enquanto o curso de Psicologia apenas seria autorizado na segunda metade da década de 1970.

Se o conhecimento psicológico no Brasil sempre caminhou ao lado da Educação, em termos nacionais, o Curso de Pedagogia foi criado em 1939, enquanto o de Psicologia seria regulamentado apenas em 1962. No caso da UFU, o Curso de Pedagogia começou a ser oferecido na FFCLU em 1960, enquanto o de Psicologia foi criado em 1976, próximo ao processo de federalização da universidade.

O dia 19 de dezembro de 1959 marca a origem do Curso de Pedagogia em Uberlândia (Lima, 2004, p. 73). A autorização de seu funcionamento se deu pelo Decreto Federal 47.736, de 02 de fevereiro de 1960, culminando com a criação da Faculdade de Filosofia, Ciências e Letras de Uberlândia (FFCLU), que também oferecia o Curso de Letras e que passaria a oferecer outros cursos, tais como o de História, Matemática e Ciências até 1969 (Fernandes, 2003).

Mas é importante ressaltar que a incorporação do Curso de Pedagogia à Universidade só ocorreu em 1969, neste caso, à Universidade de Uberlândia (UnU). Desde o início e ainda nessa época, os cursos da FFCLU eram oferecidos nas dependências do Colégio Nossa Senhora das Lágrimas, aos cuidados da Congregação das Missionárias de Jesus Crucificado. Apenas em 1978, com a federalização da universidade e o surgimento da nomenclatura Universidade Federal de Uberlândia, o Curso de Pedagogia passaria a funcionar nos campi da própria universidade.

Ao longo da década de 1960, a Psicologia ampliou sua participação no currículo, tendo alcançado o status de conteúdo obrigatório durante todo o curso de Pedagogia. Em termos de temáticas, as disciplinas abordavam o conceito e a História da Psicologia, os métodos, personalidade, vida afetiva e intelectiva, Psicologia da criança, Psicologia da adolescência, teoria behaviorista (comportamental), testes e medidas; e no final do último ano, aparecia a epistemologia genética de Jean Piaget.

A Psicologia Educacional também era oferecida em outros cursos de licenciatura no período, como disciplina pedagógica e comum a outras graduações, tais como Letras e História. Como o conteúdo da disciplina nestes cursos era previsto para apenas um ano, ele apresentava boa parte dos tópicos da matéria no curso de Pedagogia, mas de forma resumida.

As ementas e os conteúdos programáticos foram analisados a partir dos registros formais decorrentes dos programas de curso da disciplina Psicologia da Educação. Esses programas permitem conhecer a proposta inicial para o desenvolvimento da prática docente, representando o conteúdo prescrito da disciplina, porém sem garantir correspondência necessária com a realidade pedagógica. 
Os dados dos arquivos eletrônicos encontrados na Diretoria de Administração e Controle Acadêmico (Dirac) da UFU permitiram o acesso às ementas e aos programas de disciplinas da década de 1960. No caso desta pesquisa, foram analisados os programas de disciplinas relacionadas à Psicologia. Esses dados foram confrontados com dados da Revista Comemorativa do Primeiro Decênio da FFCLU (1970).

Ao comparar os conteúdos registrados nos arquivos digitalizados disponibilizados pela UFU com o programa do Curso de Pedagogia apresentado na Revista Comemorativa do Primeiro Decênio da FFCLU (1970), percebe-se que o conteúdo corresponde mais ao em vigor no final da década de 1960.

Entre os temas mais comuns estão: Definição, História e objeto da Psicologia Científica; Grandes teorias; Os métodos da Psicologia Científica; Testes e Medidas; Psicologia da Criança; Psicologia da Adolescência (mudanças fisiológicas, puberdade); Aprendizagem (natureza, definição, leis, curvas, transferência, controle); Maturação; Personalidade; Psicopatologias; Inteligência; Psicologia Diferencial; Hereditariedade e Meio; Temperamento e Caráter; As emoções; Desenvolvimento social. Ao final dos anos 60 e início dos 70, começam a aparecer tópicos específicos ligados à teoria behaviorista: Estímulo: discriminação e generalização; Condicionamento Respondente ou Clássico; Condicionamento operante ou Instrumental.

\section{As atividades de extensão em Psicologia na FFCLU entre 1965 e 1970.}

Durante a "efervescência cultural" de Uberlândia na década de 1960 continuaram surgindo novos cursos superiores e faculdades na cidade. Essa nova realidade social acompanhava as mudanças culturais sofridas no contexto estadunidense, europeu e brasileiro. Os cursos de extensão também despertaram demasiado interesse para os universitários e secundaristas de Uberlândia. No caso da Psicologia, foram seis cursos relacionados a esta área e oferecidos ao longo da década: Personalidade e Psicanálise (1965), Parapsicologia (1965), Psicopatologia (1966), Caracterologia (1966), Dinâmica de Grupo e Psicologia das Relações Humanas (1967), Biopsicologia (1969) e Psicopatologia (1970). Estes cursos eram direcionados para os próprios alunos da faculdade e, também, para professores da rede estadual e municipal. Alguns cursos como o de Personalidade e Psicanálise, em 1965, e de Psicologia das Relações Humanas, de 1967, chegaram a ter a participação de 363 e 469 alunos, respectivamente ${ }^{3}$.

Alguns cursos de extensão contavam com os próprios professores da faculdade, como o Cônego Durval Garcia, que ministrou o curso Caracterologia, discutindo temas relacionados aos Fundamentos da análise do caráter, o Complexo psico-físico na estrutura do caráter e a Descrição de caracteres, contando com a participação de 73 alunos. Outros cursos contavam com professores que vinham de outras cidades. No caso do curso de Parapsicologia, é importante registrar que ele foi ministrado pelo Padre Oscar Gonzalez Quevedo, o qual, nas décadas posteriores, tornou-se popular em todo o país, conhecido simplesmente como Padre Quevedo, a partir de suas aparições em programas televisivos de grande audiência. Esses cursos de extensão revelavam o espírito de entusiasmo com os novos conhecimentos propiciados pela criação das faculdades, incluindo a Psicologia como uma das áreas de grande interesse.

\section{As disciplinas de Psicologia no Curso de Pedagogia da FFCLU entre 1968 e 1971.}

Quanto às disciplinas propriamente ditas, elas sofriam influências advindas do parecer 251/62 do Conselho Federal de Educação (Brasil, 1963), como poderiam ser percebidas nas

\footnotetext{
${ }^{3}$ O programa do curso de extensão universitária sobre a Psicologia das Relações Humanas apresentava temas como: conhecimento da pessoa; o problema das Diferenças Individuais; a conduta e as necessidades humanas básicas; a motivação; a adaptação da conduta humana; os mecanismos de defesa; a maturidade no relacionamento humano; a modificação das atitudes; condições de maturidade.
} 
nomenclaturas das mesmas no período. Porém, a Psicologia da Educação continuava predominando como principal disciplina na área.

Os conteúdos programáticos prescritos para as disciplinas de Psicologia continham temas relacionados ao conceito e a História da Psicologia, na disciplina Psicologia Geral, no primeiro ano do Curso de Pedagogia; a Psicologia da criança e da adolescência (Psicologia do Desenvolvimento) na disciplina Psicologia da Educação do segundo ano; o Processo de Aprendizagem (Psicologia da Aprendizagem) na disciplina Psicologia da Educação do terceiro ano; e a definição de Personalidade (Psicologia da Personalidade) na disciplina Psicologia da Educação no quarto e último ano. O Quadro 2, a seguir, apresenta essa organização.

Quadro 2 - Relação de conteúdo das disciplinas de Psicologia de 1968 a 1971.

\begin{tabular}{|c|c|c|c|}
\hline Ano & Série & Disciplina & Conteúdo \\
\hline 1968 & $1^{\mathrm{a}}$ & Psicologia Geral & $\begin{array}{l}\text { 1) Introdução Geral: Conceito e História da Psicologia; os } \\
\text { rumos da Psicologia moderna; as perspectivas filosóficas; os } \\
\text { métodos da Psicologia. Psicologia e Filosofia. 2) As grandes } \\
\text { escolas. Os grandes problemas da psicologia: Reflexo e } \\
\text { Consciência. 3) Extensão da vida anímica: vida ativa, vida } \\
\text { afetiva, vida intelectiva. 4) Comportamento humano. } \\
\text { Comportamento social. 5) Psicanálise e suas várias correntes. }\end{array}$ \\
\hline 1969 & $2^{a}$ & $\begin{array}{l}\text { Psicologia da } \\
\text { Educação }\end{array}$ & $\begin{array}{l}\text { 1) Psicologia da Criança: problemas psico-biológicos; } \\
\text { problema psico-pedagógicos; problemas psico-patológicos. } \\
\text { Psicologia, Escola e Educação. Testes e medidas. 2) } \\
\text { Psicologia da adolescência: visão geral da adolescência. } \\
\text { Crises do adolescente. Mudanças psicológicas. Mudanças } \\
\text { fisiológicas. A Dinâmica da adolescência: vida intelectual; } \\
\text { vida imaginativa; vida afetiva e emotiva; vida sexual; vida } \\
\text { moral e religiosa. Caráter e temperamento. Caracterologia. }\end{array}$ \\
\hline 1970 & $3^{\mathrm{a}}$ & $\begin{array}{l}\text { Psicologia da } \\
\text { Educação }\end{array}$ & $\begin{array}{l}\text { 1) A Psicologia contemporânea. 2) O processo de } \\
\text { aprendizagem: conceito, características; importância, } \\
\text { problemas. 3) Estímulo: discriminação e generalização. 4) } \\
\text { Condições que influenciam a aprendizagem. 5) } \\
\text { Condicionamento respondente ou clássico. 6) } \\
\text { Condicionamento operante ou instrumental. 7) Outros modos } \\
\text { de aprender. 8) Aprendizagem motora. 9) Aprendizagem } \\
\text { emotiva. 10) Aprendizagem intelectiva. 11) Motivação e } \\
\text { bases experimentais. 12) Retenção e esquecimento. 13) } \\
\text { Transferência da aprendizagem. }\end{array}$ \\
\hline 1971 & $4^{a}$ & $\begin{array}{l}\text { Psicologia da } \\
\text { Educação }\end{array}$ & $\begin{array}{l}\text { 1) A Personalidade: definição, determinantes biológicos e } \\
\text { orgânicos da personalidade. Fatores constitucionais. Fatores } \\
\text { somáticos. 2) Concepções dinâmicas da personalidade. } \\
\text { Outras teorias. 3) Relação como temperamento e caráter. } \\
\text { Avaliação. 4) Psicologia Diferencial. 5) Psicologia social. 6) } \\
\text { Noções de psicopatologia. Mecanismos de ajustamento. 7) } \\
\text { Problemas gerais de psicoterapia. 8) Visão geral da psico- } \\
\text { pedagogia. 9) Higiene mental. }\end{array}$ \\
\hline
\end{tabular}

Fonte: Elaborado pelos autores, a partir de dados fornecidos pela Dirac/UFU.

Em entrevista com egressa do Curso de Pedagogia em 1970, pode-se verificar a percepção dela em relação à disciplina Psicologia da Educação nos anos finais de 1960, dado que cursou Pedagogia na FFCLU entre 1966 e 1970, tendo feito anteriormente o Curso Normal. Em seu depoimento, a entrevistada ressaltou as características da formação das normalistas 
naquele período, em que não havia tanta preocupação em fazer um curso superior ao final do magistério. Para ela, nessa época:

não tinha essa história de fazer faculdade, principalmente, aqui em Uberlândia. Você terminava o Normal, você já estava noiva, e depois você casava. Inclusive, eles falavam que Normal era curso de preparação para casamento. E o meu curso Normal foi nesse sentido mesmo. Eu não tive um curso Normal voltado para a Academia. O curso Normal deveria estar voltado para a formação da professora das séries iniciais, mas não se falava nisso no meu curso (Entrevistada, 2015).

No depoimento foi mencionado que, em seu caso, pensou em ser professora durante o Curso Normal, mas o curso direcionava-se para formar "meninas" para a sociedade. Em 1966, resolveu fazer uma faculdade, escolhendo o Curso de Pedagogia" ${ }^{4}$.

A partir do histórico escolar fornecido pela entrevistada foi possível identificar com exatidão as disciplinas específicas estudadas, com as respectivas cargas horárias, o que incluiu aquelas que estavam relacionadas à Psicologia. Deste modo, foi possível constatar que houve duas disciplinas: Psicologia Geral e Psicologia da Educação no primeiro ano do Curso, com carga horária de 120 h/a e 90 h/a, respectivamente. Nos três anos seguintes, foram oferecidas a disciplina Psicologia da Educação, com 120 h/a, cada, totalizando 570 h/a de conhecimentos relacionados à Psicologia.

Em relação aos conteúdos ministrados, destacou-se uma experiência, possivelmente singular, mas, marcante, que foi vivenciada pela entrevistada. Ela não soube identificar a disciplina específica, se no âmbito da Psicologia Geral ou da Psicologia da Educação ${ }^{5}$, porém, os conteúdos programáticos prescritos encontrados permitiram inferir que se tratava em verdade de uma disciplina denominada para além daquelas, nomeada, Psicologia Especial, considerando os conteúdos apresentados conforme exposto no Quadro 3 a seguir.

Quadro 3 - Listagem de conteúdos de Programa de Psicologia Especial de 1966.

\begin{tabular}{|c|c|c|}
\hline Ano & Disciplina & Conteúdo \\
\hline 1966 & Psicologia Especial & $\begin{array}{l}\text { 1. Generalidades. Noções de anatomia e Fisiologia do Sistema } \\
\text { nervoso. Psicologia. Noções Gerais. Psicologia Experimental ou } \\
\text { Científica. 2. Estudo das Faculdades mentais: Atenção, Memória, } \\
\text { Consciência, Senso-percepção. Imaginação. Afetividade. Vontade. } \\
\text { Atividade. Associação de Ideias. Juízo. Inteligência. Instintos. } \\
\text { Personalidade. 3. Testes. Noções Gerais. Testes Principais. 4. O } \\
\text { homem normal. A Vida psíquica do homem normal. A estrutura da } \\
\text { vida psíquica. Os grandes dinamismos que regulam a vida psíquica. } \\
\text { 5) Doenças mentais: oligofrenia, epilepsia, esquizofrenia, psicose } \\
\text { maníaco-depressiva, parafrenia, paranóia, psicoses degenerativas, } \\
\text { psicoses tóxicas, psicoses de situação. Reativas, traumáticas, } \\
\text { psicoses sifilíticas, psiconeurose e Órgano neurose, personalidades } \\
\text { psicopáticas. 6) Psicanálise: Noções Gerais. Psicoterapia. }\end{array}$ \\
\hline
\end{tabular}

Fonte: Elaborado pelos autores, a partir de dados fornecidos pela Dirac/UFU.

\footnotetext{
${ }^{4}$ No início de seu depoimento, a entrevistada teve dificuldade em separar as disciplinas estudadas no Curso Normal daquelas estudadas no Curso de Pedagogia, o que foi justificado por se tratar do mesmo espaço físico, as mesmas pessoas, inclusive, os mesmos professores, dado que a FFCLU funcionava nas mesmas dependências da Escola Normal.

${ }^{5}$ Os conteúdos prescritos nos documentos do período também apresentam a alternância da denominação Psicologia da Educação e Psicologia Educacional, e não apenas Psicologia da Educação como aparece no histórico escolar da entrevistada.
} 
Segundo a entrevistada, o professor da disciplina foi um psiquiatra da cidade, o qual ministrou conteúdos relacionados ao tema dos distúrbios psicológicos. Os alunos precisavam fazer visitas a um sanatório da cidade, nas quais cada um era responsável em acompanhar um paciente e apresentar o diagnóstico do distúrbio no final da disciplina.

Então, eu me lembro bem da Psicologia. Era uma das experiências que eu mais me lembro. Então, quem dava aula de Psicologia era um psiquiatra (...). E o que ele trabalhou? Ele não trabalhou nada de Psicologia Educacional. Ele trabalhou distúrbios psicológicos. Ele deu um trabalho pra gente, nada a ver, para um Curso de Pedagogia, para uma menina do primeiro ano. A gente tinha que ir no sanatório: ele deu um "doido" para cada um de nós. A gente ia no sanatório e a gente ficava conversando com esse "doido". "Doido" porque era sanatório, pessoa que tinha algum distúrbio, e a gente tinha que, ao final do trabalho, falar, descobrir o distúrbio. Pensa se isso é possível? Se para um psicólogo, para um psiquiatra, é difícil um diagnóstico... Aí, eu converso lá com uma pessoa, várias semanas, vou lá uma vez por semana, converso, e depois tenho que falar o que ela tinha, se ela era esquizofrênica, se ela tinha... [...] Então, eu não sei se ela tinha a psicose maníaco-depressiva e eu falei que era esquizofrenia, ou vice-versa, eu lembro que eu errei, mas eu lembro que o erro estava entre esses dois diagnósticos (Entrevistada, 2015).

Nesse caso, percebe-se o direcionamento da disciplina para estudos relacionados à Psicologia Clínica, sem ênfase nos conhecimentos específicos mais comuns à Psicologia da Educação (Psicologia Educacional e Escolar). Ela também citou um professor de Goiânia, no Estado de Goiás, o qual ministrava palestras interessantes sobre Psicologia.

Era uma Psicologia voltada para distúrbios psicológicos. Porque o que eu me lembro do professor é que ele falava assim: que a gente ia acumulando caixinhas, era o exemplo que ele usava; e essas caixinhas eram... Qual era a analogia que ele fazia? Não lembro... Lembro dos exemplos que ele dizia, assim: você sai e não sabe se deixou a luz acesa, se deixou o ferro ligado, acho que no sentido do "stress", ele queria chegar na situação do "stress". E essas caixinhas seriam pontos que estariam somando no meu "stress". E ele deu essas palestras, e foi muito bom! A gente gostou muito das palestras desse professor (Entrevistada, 2015).

Nesse sentido, esse conteúdo foi a principal lembrança de conhecimentos de Psicologia oferecidos na graduação, a qual apresentava a Psicologia em todos os anos do curso. Ao ser indagada sobre teorias específicas, a entrevistada mencionou lembrar dos conteúdos de Freud por serem avaliados ao final do primeiro ano, pois os distúrbios psicológicos estudados eram abordados por meio da teoria psicanalítica. Quanto à teoria behaviorista e ao nome de Skinner, lembrou dos conceitos de "reflexo condicionado". Ela ressaltou que não estudou a teoria de Piaget durante o curso, apesar de que vimos que constava dos conteúdos previstos, com lembrança de Piaget e de Vigotski, apenas a partir dos cursos de pós-graduação que fez.

- Então o Freud a senhora lembra que estudou no curso... 
- Eu me lembro, o que eu estudei: Freud e distúrbios psicológicos.

- Psicopatologias!?

- Psicopatologias. No primeiro ano, é o que eu me lembro. Os outros anos... deve ter tido mais Psicologia Educacional. Mas eu não me lembro; não me lembro, inclusive, do Normal.

- Por exemplo, o Piaget?

- Não!

- A senhora não consegue lembrar ou a senhora acha que não teve o conteúdo de Piaget?

- Não teve! Não teve Piaget.

- A senhora não estudou Piaget!

- Não estudei Piaget.

- Então, agora eu vou falar um autor que é mais difícil, pois é mais recente: Vigotski?

- Não. Nada.

- Porque ele é mais dos anos noventa...

- Psicopedagogos, ninguém.

- Agora, o Skinner, que estava chegando na época, Behaviorismo...

- Talvez.

- Os ratinhos, estímulo e resposta...

- Talvez... Talvez o Skinner... Reflexo condicionado, talvez o que você citou. Mas Piaget e Vigotski, eu vi quando eu já era... Piaget, eu vi quando eu comecei a lecionar, que eu estava lá na escola de psicogenética, e a gente estudava sobre Piaget. E Vigotski, já na faculdade... aliás, nem na faculdade; na pós-graduação, que eu tive uma disciplina, Pensamento e Linguagem, que a gente viu Vigotski e Piaget.(...) Não, não tinha Piaget, nem Vigotski. Piaget, eu vi como profissional, e Vigotski, eu vi no mestrado (Entrevistada, 2015).

No decorrer da entrevista, foram apresentadas algumas ementas e conteúdos programáticos do período, o que fez vir à lembrança mais alguns conteúdos específicos relacionados às teorias psicológicas, como condicionamento clássico ou respondente, e condicionamento operante (Behaviorismo), e os conceitos de Id, Ego e Superego (Psicanálise).

Em relação às práticas pedagógicas dos docentes em sala de aula, a principal lembrança da depoente remetia à experiência desse trabalho prático nas visitas ao sanatório proposto pelo Professor-psiquiatra, assim como as palestras do outro professor de Psicologia. Ela também ressaltou uma forma de avaliação de aprendizagem, pois, ao término das atividades de Psicologia do primeiro ano, a Irmã Ilar Garotti, professora e diretora da faculdade nesse período, aplicou uma prova de conhecimento de Psicologia. Os alunos tiveram acesso a um livro sobre Freud e fizeram uma avaliação em forma de arguição oral, na qual ela teria se saído muito bem.

- Bom, e a avaliação da disciplina? A madre Ilar mandou a gente ler um livrinho assim do Freud, eu não lembro o título do livrinho. Um livreto do Freud.

- Que o próprio Freud escreveu ou sobre o Freud?

- Sobre o Freud. E a gente tinha que fazer uma prova. Uma prova sobre esse livro. A Ilar fez a entrevista. Entrevista não, uma prova. Ela fazia umas perguntas sobre o livro que ela mandou ler.

- Mas essa prova...?

- Oral. 
- E concentrou toda a nota nessa prova?

- A nota final foi baseada nesta prova. As notas iniciais deviam ter... A nota final foi essa prova. Eu não me lembro o nome do livro, eu lembro que era um livro preto, muito "gostoso" de ler, foi quando eu tomei contato com o Freud, eu gostei demais da leitura que eu fiz, e eu me lembro que eu fui muito bem na prova: eu tirei dez, e ela me falou que eu era muito inteligente, "nossa, você precisa aproveitar sua inteligência, você é um menina muito inteligente" (Entrevistada, 2015).

Quanto ao cumprimento da ementa e dos conteúdos programáticos prescritos, como parte da compreensão da relação entre conteúdo prescrito e realidade pedagógica, a depoente mencionou não haver ementas naquela época, ou que, pelo menos, os alunos não tinham acesso a essa informação no início das aulas de determinada disciplina.

- A senhora lembra se os professores eram muito fiéis à ementa?

- A gente não tinha acesso à ementa.

- Não tinha?

- Não.

- O que o professor levava era o que era ensinado...

- Aula por aula. A gente não tinha acesso à ementa não. Então, o Curso de Pedagogia, para compor o histórico, em seu início, assim que eu entrei, 1966, era uma continuação do Curso Normal. Muitos professores eram os mesmos (Entrevistada, 2015).

Ao ser indagada sobre a relação com outras disciplinas, a depoente destacou não haver interdisciplinaridade naquele período. Entretanto, contou sobre a importância da chegada de novos docentes, recém-formados, provenientes da Universidade Estadual de Campinas (Unicamp), o que teria representado uma mudança importante no curso no final dos anos de 1960. Esses novos professores, segundo a entrevistada, apresentavam conhecimento mais atualizado quanto aos conteúdos e manifestavam comportamentos considerados modernos para a época ${ }^{6}$.

\section{Considerações finais}

Depreende-se que no período estudado, a primeira década de funcionamento do Curso de Pedagogia na FFCLU, entre 1960 e 1970, que os planos de cursos formais, com ementas, objetivos e bibliografia ainda não estavam consolidados. Influenciadas pelo parecer 251/62 (Brasil, 1963) apareceram as nomenclaturas de Psicologia, Psicologia Geral, Psicologia da Educação, Psicologia Educacional e Psicologia Especial. A Psicologia permaneceu como disciplina de fundamentos nos quatro anos do curso de Pedagogia, chegando a 570 horas/aula, em um curso de 2.800 horas, representando um quinto dos conteúdos oferecidos.

O conteúdo prescrito trazia conhecimentos gerais de Psicologia, como Ciência e História, na disciplina Psicologia Geral do primeiro ano; conteúdos de Psicologia do Desenvolvimento (da criança e do adolescente), em Psicologia da Educação do segundo ano; de Psicologia da Aprendizagem (com conteúdo de Psicologia Comportamental), em Psicologia da Educação do terceiro ano, e de Psicologia da Personalidade (com uso de testes e medidas, psicologia diferencial e psicologia do ajustamento) na Psicologia da Educação do quarto ano.

\footnotetext{
${ }^{6}$ A depoente contou que uma professora vinda de Campinas usou minissaia no primeiro dia de aula, e ao sentarse, cruzou as pernas. Como a maioria das professoras do período eram freiras, esse comportamento chamou muito a atenção por ser autêntico e inovador.
} 
Além dos conteúdos básicos relacionados à área de Psicologia Educacional, a disciplina nomeada Psicologia Especial apresentava conhecimentos de Psicopatologia.

Ao considerar os conteúdos ministrados, destacaram as teorias de Freud e Skinner. A teoria humanista de Carl Rogers ainda não se destacava em disciplinas de Psicologia. E estudos de Vigostski e Wallon eram desconhecidos nesse período.

No caso das práticas pedagógicas em sala de aula, destacaram as aulas expositivas com predominância do uso do quadro e giz. Havia aulas com atividades

práticas, como o exemplo da visita ao sanatório, em função do docente da disciplina de Psicologia possuir formação médica. Aparentemente, não era usual que os professores apresentassem as ementas e mesmo programas de suas disciplinas aos alunos; a forma de avaliação da aprendizagem predominante era por meio de provas tradicionais, escritas e orais, alternando com alguns trabalhos; na relação com outras disciplinas, não havia interdisciplinaridade. A bibliografia continuava a depender da definição do próprio professor responsável pela disciplina, não sendo possível estabelecer obras comuns ao período.

A pesquisa permitiu perceber a centralidade da Psicologia na formação dos pedagogos na Faculdade de Filosofia, Ciências e Letras de Uberlândia na primeira década de funcionamento do Curso de Pedagogia, mesmo com as dificuldades quanto à qualificação docente, o que limitou o aprofundamento das especificidades da temática educacional.

\section{Referências}

BORGES, B.G. A disciplina História da Educação na Universidade Federal de Uberlândia/MG (1960-2000). Dissertação (Mestrado em Educação). Uberlândia/MG: Universidade Federal de Uberlândia, Programa de Pós-Graduação em Educação. 2013.

BOURDIEU, P. A ilusão biográfica. In: FERREIRA, M.M.; AMADO, J. Usos \& abusos da história oral. Rio de Janeiro: Editora da FGV. 2005. p. 183-191.

BRASIL. Congresso Nacional. Lei 6.532, de 24 de Maio de 1978. Acrescenta e altera dispositivos no Decreto-Lei 762, de 14 de agosto de 1969, que "autoriza o funcionamento da Universidade de Uberlândia", e dá outras providências. Disponível em: https://www2.camara.leg.br/legin/fed/lei/19701979/lei-6532-24-maio-1978-365781-norma-pl.html. Acesso em: 18 abr. 2020.

BRASIL. Ministério da Educação. Conselho Federal de Educação. Parecer 251/62. Currículo mínimo e duração do curso de Pedagogia. Documenta, Brasília. (1-11). 1963. p.59-65.

CAETANO, C.G.; DIB, M.M.C. A UFU no imaginário social. Uberlândia/MG: Universidade Federal de Uberlândia. 1988.

CERTEAU, M. A operação histórica. In: LE GOFF, J. e NORA, P. História: novos problemas. Trad. Theo Santiago. 2a ${ }^{\mathrm{a}}$. ed. Rio de Janeiro: Francisco Alves, 1979.

CHERVEL, A. História das Disciplinas escolares. Teoria \& Educação, n.2. Porto Alegre: Panorâmica. 1990. p.177-229.

FERNANDES, M.D.S. As origens do Curso de Pedagogia: um capítulo do Ensino Superior em Uberlândia, Minas Gerais (1957-1963). Dissertação (Mestrado em Educação). Uberlândia/MG: Centro Universitário do Triângulo, Programa de Pós-Graduação em Educação. 2003.

GOODSON, I. As políticas de currículo e de escolarização: abordagens históricas. Trad. de Vera Joscelyne. Petrópolis/RJ: Vozes. 2008. 
GOODSON, I. Currículo: teoria e história. Trad. Attílio Brunetta. 9a ed. Petrópolis/RJ: Vozes. 2010.

GUIMARÃES, R.M.C. O percurso institucional da disciplina "História da Educação" em Minas Gerais e o seu ensino na Escola Normal Oficial de Uberaba (1928-1970). Tese (Doutorado em Educação) Uberlândia/MG. Universidade Federal de Uberlândia, Programa de Pós-Graduação em Educação. 2012. 302p.

LIMA, L.R. Psicologia da Educação no Curso de Pedagogia da UFU: retrospectiva histórica da disciplina. Dissertação (Mestrado em Educação). Uberlândia/MG: Universidade Federal de Uberlândia, Programa de Pós-Graduação em Educação. 2004.

MOREIRA, A.F.L. Prefácio. In: GOODSON, I. As políticas de currículo e de escolarização: abordagens históricas. Trad. de Vera Joscelyne. Petrópolis/RJ: Vozes. 2008. p. 7-11.

PROST, A. A história como compreensão. In: Doze lições sobre a história. Trad. Guilherme João de Freitas Teixeira. Belo Horizonte: Autêntica Editora. 2008. p.133-152.

SANTOS, M.T. Percurso e situação do ensino da História da Educação em Portugal. In: GATTI JR., D.; PINTASSILGO, J. (Orgs.). Percursos e desafios da pesquisa e do ensino da História da Educação. Uberlândia-MG: Edufu. 2007. p. 75-97.

SAVIANI, D. A Pedagogia no Brasil: história e teoria. Campinas/SP: Autores Associados, 2006.

SILVA, T.T. Prefácio. In: GOODSON, I. Currículo: teoria e história. Trad. Attílio Brunetta. $9^{a}$ ed. Petrópolis, RJ: Vozes, 2010. p.7-13.

TARDIF, M. O projeto de criação de uma ciência da educação no século XX. In: GAUTHIER, C.; TARDIF, M. A Pedagogia. Teorias e práticas da Antiguidade aos nossos dias. Trad. Lucy Magalhães. Pretropólis/RJ: Vozes. 2020. p.353-367.

THOMPSON, P. História Oral e Contemporaneidade. Trad. Andréa Zhouri e Lígia Maria Leite Pereira. História Oral, v.5. jun./2002, p.09-28. Disponível em: http://revista.historiaoral.org.br/index.php?journal=rho\&page=issue\&op=view\&path $\% 5 \mathrm{~B} \% 5 \mathrm{D}=8$. Acesso em 17 abr. 2020.

UNIVERSIDADE FEDERAL DE UBERLÂNDIA. Revista Comemorativa do Primeiro Decênio da FFCLU. Uberlândia/MG: UFU. 1970.

WARDE, M.J. Questões Teóricas e de Método: a História da Educação nos marcos de uma História das Disciplinas. In: SAVIANI, D.; LOMBARDI, J.C.; SANFELICE, J.L. (Orgs.). História e História da Educação: o debate teórico-metodológico atual. Campinas/SP: Autores Associados. 1998. 